\title{
Phosphorus fractions depletion in the rhizosphere of young and adult maize and oilseed rape plants
}

\author{
Ricardo A. Cabeza ${ }^{1,2 *}$, Kyi Myint ${ }^{1}{ }^{\dagger}$, Bernd Steingrobe ${ }^{1}$, Christos Stritsis $^{1}$, Joachim Schulze ${ }^{1}$ \\ and Norbert Claassen ${ }^{1}$
}

${ }^{1}$ Department of Crop Sciences, Section of Plant Nutrition and Crop Physiology, Georg August University, Göttingen, Germany. ${ }^{2}$ Departmento de Producción Agrícola, Facultad de Ciencias Agrarias, Universidad de Talca, Casilla 747, Talca, Chile. *Corresponding author: rcabeza@utalca.cl

$\dagger$ In memoriam of Dr. Kyi Myint.

\begin{abstract}
In alkaline soils, where most of the $\mathrm{P}$ is acid soluble, we hypothesize that species that acidify the rhizosphere such as oilseed rape, are more efficient to use soil $\mathrm{P}$ than for example maize. In field experiments, adult maize plants extracted more P per unit of root than young plants. Here we hypothesize that older plants access P fractions that younger plants were not able to. Thus, the aim of this research was to study the P fractions used by maize and oilseed rape growing in an acid sandy and a neutral loamy soil and how plant age might affect it. A special pot system was developed in which P uptake by the plants came from roots that grew freely in soil. To obtain rhizosphere soil, a portion of the roots was concentrated to form a root mat on a planar soil surface covered by a fine nylon mesh. Cutting the soil on the other side of the mesh into slices gave rhizosphere soil at different distances from the root surface. We examined the $\mathrm{P}$ fractions used by maize and oilseed rape at three growth stages by measuring the depletion of three inorganic $\left(\mathrm{P}_{\mathrm{i}}\right)$ and two organic $\left(\mathrm{P}_{\mathrm{o}}\right) \mathrm{P}$ fractions in the rhizosphere. Oilseed rape did not affect the $\mathrm{P}_{\mathrm{o}}$ fractions in any of the two soils, and maize only in the acid soil. Both species in both soils depleted only the alkali soluble $\mathrm{P}_{\mathrm{i}}$ fraction. The degree of depletion was between $12-26 \%$. The acid soluble $\mathrm{P}_{\mathrm{i}}$ was not depleted by neither oilseed rape nor maize. Plant age had no effect on $\mathrm{P}$ fraction depleted or on the degree of depletion.
\end{abstract}

Keywords: Plant age, plant species, depletion of P fractions 


\section{Introduction}

Only a small portion of soil $\mathrm{P}$ available for plant on a short-term basis and therefore $\mathrm{P}$ taken up by crops in one growing season is small compared to total $\mathrm{P}$ content of the soil. This is because a large amount of soil $\mathrm{P}$ is found as organic matter (Richardson and Simpson, 2011) and an important part of inorganic $P$ is more or less strongly adsorbed to soil particle surfaces that contain $\mathrm{Fe}, \mathrm{Al}$ or $\mathrm{Ca}$ or the $\mathrm{P}$ is precipitated with those cations (Holford, 1997). Organic P has to be mineralized before plants can take it up and the strongly bound inorganic $\mathrm{P}$ is of low mobility and furthermore kinetics of its release into the soil solution or solubilization is slow.

To characterize the plant available $\mathrm{P}$ and $\mathrm{P}$ bonding in soil, sequential chemical extraction procedures have widely been used (Chang and Jackson, 1957; Hedley et al., 1982; Redel et al., 2016). In all the procedures, an acid extraction is preceded by an alkali extraction. In the alkali $\left(\mathrm{NaHCO}_{3}, \mathrm{NaOH}\right)$ extraction no $\mathrm{Ca}$ bound $\mathrm{P}$ but $\mathrm{Fe}$ - or $\mathrm{Al}-$ bound $\mathrm{P}$ is released or dissolved (Chang and Jackson, 1957). Therefore, alkali soluble $\mathrm{P}$ is often designated as Fe/Al-P. In the following acid extraction step $\left(\mathrm{HCl}\right.$ or $\left.\mathrm{H}_{2} \mathrm{SO}_{4}\right)$ Ca-bound $\mathrm{P}$ is released (Chang and Jackson, 1957). Therefore, the acid soluble $\mathrm{P}$ fraction is often designated as Ca-P, but actually this extraction step dissolves $\mathrm{P}$ fractions which were not dissolved by the alkali extractant which not always is necessarily Ca-bound $\mathrm{P}$ only.

To overcome low availability of soil P, plants can actively increase the availability of low available $\mathrm{P}$ fractions by altering the $\mathrm{pH}$ of the rhizosphere (Gahoonia et al., 1992a; Hoffmann et al., 1994), releasing $\mathrm{H}^{+}$in the case of legumes, exuding phosphatase, which catalyses the mineralization of organic $\mathrm{P}$ (Helal, 1990), or releasing organic acids as has been shown for very efficient plants that form cluster roots (Delgado et al., 2015).
For the same species, the ability to increase the $\mathrm{P}$ availability may also change with growth stage as shown for sugar beet (Claassen et al., 1990) and for maize (Bhadoria et al., 2001). The latter found on a low P Oxisol where older maize plants were more efficient to acquire $\mathrm{P}$ than younger ones because they increased the $\mathrm{P}$ uptake rate per unit of root by six times. We hypothesise that older maize plants were able, e.g. through root exudates, to mobilize and deplete $\mathrm{P}$ fractions in the rhizosphere roots of younger plants were not able to. In Oxisols, as used in the experiment mentioned above, $\mathrm{P}$ is mostly alkali soluble (Bhadoria et al., 2002) and its mobilization is thought to be mainly by desorption, ligand exchange or $\mathrm{pH}$ increase (Hoffmann et al., 1994). However, this strategy may not work in soils of neutral to alkaline $\mathrm{pH}$ where $\mathrm{P}$ will be predominantly acid soluble, probably bound to $\mathrm{Ca}$ (Bhadoria et al., 2002). For Ca bound $\mathrm{P}, \mathrm{H}^{+}$exudation may enhance mobilization of soil $\mathrm{P}$ (Gahoonia et al., 1992b, 1992a). Therefore, P mobilization strategies of plants may be effective in one soil but not in another of different $\mathrm{pH}$ controlling $\mathrm{P}$ bonding. We furthermore hypothesize that plants that acidify the rhizosphere, such as oilseed rape (Hoffland et al., 1989), will be more effective than maize in depleting acid soluble $\mathrm{P}$ in the rhizosphere of neutral to alkaline soils.

The aim of this study was to investigate which P fractions in soil are used by plants by measuring their depletion in the rhizosphere and whether the P fractions used differ among plant species or with plant age. Furthermore, since soil chemical properties can influence the P bonding in soil (Adhami et al., 2013) and thereby the plants ability to mobilize soil $\mathrm{P}$, we evaluate the $\mathrm{P}$ depletion in two contrasting soils which differ in their $\mathrm{P}$ bonding, $\mathrm{pH}$, organic matter content and texture. 
To achieve this aim, maize and oilseed rape were grown on two soils from northern Germany. An acid sandy Regosol (5\% clay, $84 \%$ sand, $\mathrm{pH}\left(\mathrm{CaCl}_{2}\right) 5.5$ and CAL P (Calcium-Acetate-Lactate extractable P) of $70 \mathrm{mg} \mathrm{P} \mathrm{kg}^{-1}$ (ca. $30 \mathrm{mg} \mathrm{P} \mathrm{kg}^{-1}$ Olsen P) and a neutral loamy Eutric Fluvisol (16\% clay, 23\% sand, $\mathrm{pH}\left(\mathrm{CaCl}_{2}\right) 7.2$ and CAL P of $63 \mathrm{mg} \mathrm{P} \mathrm{kg}{ }^{-1}$ (ca. $27 \mathrm{mg}$ $\mathrm{P} \mathrm{kg}^{-1}$ Olsen P) were used. Plants were harvested on three occasions during a 70 day pot experiment for maize and 58 day for oilseed rape. At each of the three harvests we obtained rhizosphere soil and measured the depletion of different $\mathrm{P}$ fractions as determined by a sequential $\mathrm{P}$ fractionation scheme as proposed by Hedley et al. (1982). We obtained rhizosphere soil, because of its low mobility in soil $\mathrm{P}$ is only depleted in a narrow layer around the root of about $1 \mathrm{~mm}$ (Hendriks et al., 1981). To our knowledge, there is limited information about the use of different soil $\mathrm{P}$ fractions by oilseed rape and maize as affected by plant age and soil properties.

\section{Materials and Methods}

\subsection{Description of the experiment}

The pot experiment was performed with $5 \mathrm{~kg}$ soil in 6 -L pots, in which maize (Zea mays L., cv. Cascadas) and oilseed rape (Brassica napus L., cv. Mozart) were grown. The experiment was carried out in a screen house except during rain, when all pots were kept in a glasshouse. No P fertilizer was applied to the pots, but a basal fertilization supplied the following: $200 \mathrm{mg} \mathrm{N}$ $\mathrm{kg}^{-1}$ as $\mathrm{Ca}\left(\mathrm{NO}_{3}\right)_{2}, 200 \mathrm{mg} \mathrm{K} \mathrm{kg}{ }^{-1}$ as $\mathrm{K}_{2} \mathrm{SO}_{4}$ and $50 \mathrm{mg}$ $\mathrm{Mg} \mathrm{kg}^{-1}$ as $\mathrm{MgSO}_{4} \cdot 7 \mathrm{H}_{2} \mathrm{O}$.

\subsection{Plant growing conditions}

The objective of the experimental set up was to obtain rhizosphere soil at different ages of plants that were growing under almost normal conditions in the 6- $\mathrm{L}$ pots with only a small restriction of the root system. The rhizosphere soil was obtained from a dense root mat, simulating a planar root surface. The experimental set up is shown in Figure 1. Briefly, one portion of about $200 \mathrm{~g}$ of the $5 \mathrm{~kg}$ soil was filled into a plastic cylinder ( $6.4 \mathrm{~cm}$ diameter, $5 \mathrm{~cm}$ high) and the upper and lower ends were covered by a fine $(30 \mu \mathrm{m})$ nylon mesh that allowed root hairs but not roots to enter the cylinder. The cylinder was then buried in the corresponding 6-L pot. A large funnel filled with soil was placed above the plastic soil cylinder and $50 \%$ of the roots of pre germinated seedlings were placed outside and $50 \%$ inside the funnel. The roots inside the funnel were guided towards the top of the soil cylinder, where they concentrated forming a dense planar mat of roots on the nylon mesh. Cutting the soil on the other side of the nylon mesh in thin slices gave rhizosphere soil at different distances from the root surface.

Phosphorus uptake by the plants was mainly by the root growing freely in soil, while P uptake from the root mat was negligible because of the small root surface area in contact with the soil.

Seeds of maize and oilseed rape were germinated in moist paper towels. Maize seedlings were transplanted into the pots one week after germination. In order to accelerate root branching of oilseed rape the tip of the main root was cut about $20 \mathrm{~mm}$ from the base, placed in a plate with nutrient solution and covered with paper towel to prevent exposure to light. Two weeks later, the plants were transplanted into the experimental pots placing $50 \%$ of the root branches outside and $50 \%$ inside the funnel (Figure 1).

The experiment was designed to allow for three consecutive harvests for each treatment. In order to have enough shoot and root material in the early growth stages but no strong competition among plants at later growth stages the number of plants varied according to harvest time. Thus 6,3 and 2 maize plants 
per pot and 9, 6 and 3 oilseed rape plants per pot were transplanted for the first, second and third harvest, respectively. The pots were irrigated daily with deionized water to a gravimetric water content of $15 \%$ for the Regosol and $18 \%$ for the Eutric Fluvisol. This water content was close to field capacity.

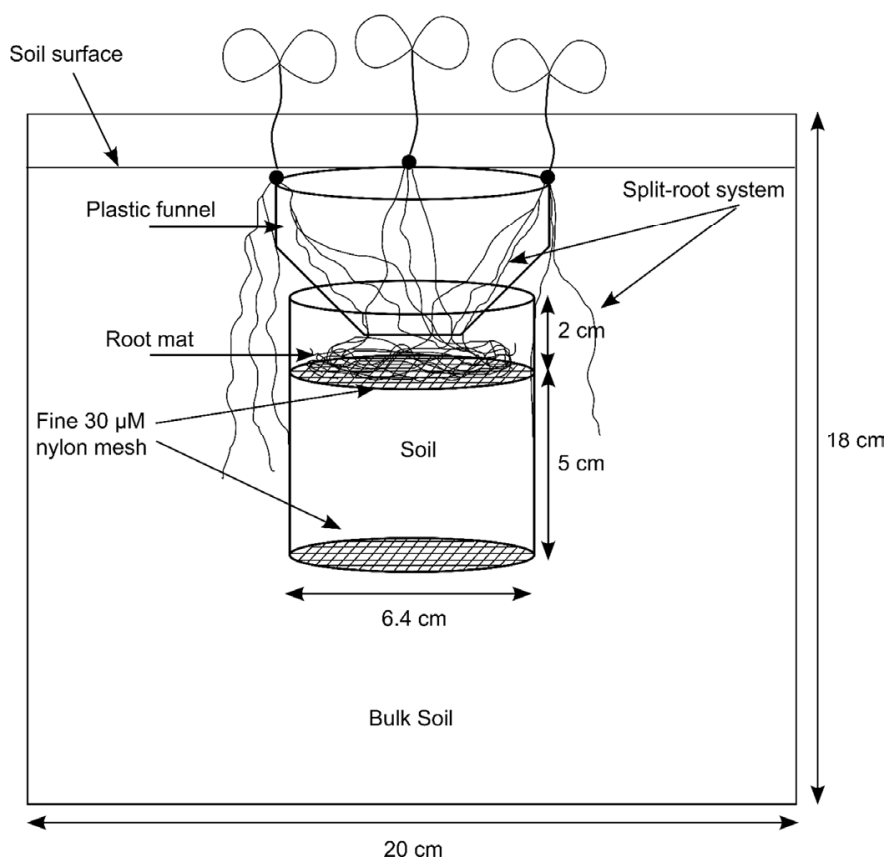

Figure 1. Schematic representation of the pot system. A PVC cylinder was inserted in the pot containing soil with the same characteristics as the surrounding soil, the PVC cylinder was covered with a fine nylon mesh (mesh size $=30 \mu \mathrm{m})$ in the upper and lower ends to prevent roots to enter into the cylinder and to avoid a direct contact of the root mat with rhizosphere soil in the upper part of the cylinder. To form a root mat over the mesh the roots were directed to it with the help of a funnel as show in the figure.

\subsection{Plant and soil sampling}

Plant shoots for determination of above ground biomass and $\mathrm{P}$ concentration were harvested at $24,42,70$ days after transplanting (DAT) for maize and 28, 42, 56 DAT for oilseed rape.

At harvest, the dense root mat that had formed over the nylon mesh was detached carefully with a sharp knife. Then the nylon mesh was removed from the plastic cylinder and the upper part of the soil column was cut into
10 slices of $1 \mathrm{~mm}$ thickness parallel to the root mat. However in maize, some soil was found adhering to the mesh which was considered to be the rhizosphere soil. To obtain the $1 \mathrm{~mm}$ slices, $1 \mathrm{~mm}$ thick plastic discs were successively pushed into the bottom of the soil cylinder and the soil emerging at the top was cut by a planar knife. The accuracy of the slicing technique was monitored by recording the weight of each slice. These soil samples were placed in small glass bottles, air dried and weighed. The rhizosphere soil was the 
soil was the soil layer in direct contact with the mesh, which in the case of maize was the soil attached to the mesh by root hairs and in the case of oilseed rape was the soil layer from 0 to $1 \mathrm{~mm}$, i.e. the first $1 \mathrm{~mm}$ slice. The combined soil sample from slices 7 - 10 was considered to be bulk soil, because no further changes in P concentration occurred between slice 7 and slice 10 . The rhizosphere soil and the bulk soil were analyzed separately by sequential P fractionation.

\subsection{Analytical procedure}

\subsubsection{Plant material}

After harvesting, plant shoot (leaves and stems) material was dried at $65{ }^{\circ} \mathrm{C}$ to constant weight. Subsamples of plant dry matter were digested in concentrated $\mathrm{HNO}_{3}$ at $180{ }^{\circ} \mathrm{C}$ and the $\mathrm{P}$ concentration in the solution was measured colorimetrically using the molybdenum vanadate method (Scheffer and Pajenkamp, 1952). Phosphorus uptake (PU) was calculated from shoot dry matter and shoot $\mathrm{P}$ concentration.

\subsubsection{Soil}

Before the start of the experiment, soil samples were analyzed for available phosphorus (P), $\mathrm{pH}$ and texture. Plant available $\mathrm{P}$ was assumed to be that extracted by calcium-acetate-lactate (CAL P) (Schüller, 1969). Soil $\mathrm{pH}$ was measured in $0.01 \mathrm{M} \mathrm{CaCl}_{2}(1: 2.5)$ and soil texture determined by means of the hydrometer method (Day, 1965).

\subsubsection{Phosphorus fractionation}

Phosphorus fractions were obtained by a modified extraction procedure based on the method proposed by Hedley et al. (1982). The last two extraction steps, though, with concentrated $\mathrm{HCl}$ and $\mathrm{H}_{2} \mathrm{SO}_{4}+\mathrm{H}_{2} \mathrm{O}_{2}$ were omitted since the $\mathrm{P}$ thereby extracted is usually not used by plants. The fractionation procedure was as follows: air dried rhizosphere and bulk soil samples from the pot experiment were milled and subsequently sieved to $500 \mu \mathrm{m}$. Then $0.5 \mathrm{~g}$ were extracted sequentially with $30 \mathrm{~mL}$ of $0.5 \mathrm{M} \mathrm{NaHCO}_{3}(\mathrm{pH} 8.5$ ), $30 \mathrm{~mL}$ of $0.1 \mathrm{M} \mathrm{NaOH}$ and $30 \mathrm{~mL}$ of $1 \mathrm{M} \mathrm{HCl}$ using a $50 \mathrm{~mL}$ centrifuge tube. Each extraction step consisted in a shaking of $16 \mathrm{~h}$, centrifugation at 25,000 $\mathrm{g}$ for $10 \mathrm{~min}$ at $10{ }^{\circ} \mathrm{C}$ and thereafter the supernatant was decanted and filtered with a $0.45 \mu \mathrm{m}$ nitrocellulose filter. The soil residue in the centrifugation tube was then re-suspended with the next extractant. The supernatants were analysed for dissolved inorganic $\mathrm{P}\left(\mathrm{P}_{\mathrm{i}}\right)$ and total $\mathrm{P}\left(\mathrm{P}_{\mathrm{t}}\right)$. Inorganic $\mathrm{P}$ was determined directly in the supernatants. Total $\mathrm{P}\left(\mathrm{P}_{\mathrm{t}}\right)$ was obtained by digesting the organic matter in the extracts with ammonium persulfate and $5 \mathrm{~mL} 0.9 \mathrm{M} \mathrm{H}_{2} \mathrm{SO}_{4}$ for 60 $\min$ at $120^{\circ} \mathrm{C}$ in an autoclave. The $\mathrm{P}$ concentration in all extracts was determined colorimetrically according to the method of Murphy and Riley (1962). Organic $\mathrm{P}\left(\mathrm{P}_{\mathrm{o}}\right)$ fraction was then calculated as the difference between $\mathrm{P}_{t}$ and $\mathrm{P}_{\mathrm{i}}$.

\subsection{Statistics}

Statistical analysis was performed using Statistica 9.0 (StatSoft, Inc. Tulsa, USA). The experiment was conducted in a completely randomized design with four replicates. Differences in shoot biomass, P concentration, $\mathrm{PU}$ and $\mathrm{P}$ fractions over time were analyzed by one way ANOVA with harvest as the main factor. The ANOVA test was followed by a Tukey test at the $\mathrm{P}<0.05$ level of significance to compare means between harvests. The concentrations of different $\mathrm{P}$ fractions in the rhizosphere and in bulk soil were compared using the t-test $(\mathrm{P}<0.05)$. 


\section{Results}

\subsection{Plant growth and P uptake of maize and oilseed rape}

This experiment was designed to get rhizosphere soil from plants that grew almost normal without major restrictions for a longer period of time. The results on plant growth and $\mathrm{P}$ uptake shown below will show this. The results of Table 1 show that maize grew more in the Regosol than in the Eutric Fluvisol while the shoot biomass of oilseed rape was almost the same in both soils. Both species in both soils increased the shoot biomass per pot until the last harvest even though the number of plants decreased from the first to the third harvest.

The shoot $\mathrm{P}$ concentration of maize decreased from $2.4 \mathrm{mg} \mathrm{kg}^{-1}$ to $1.6 \mathrm{mg} \mathrm{kg}^{-1}$ in the Regosol but on the Eutric Fluvisol stayed the same $\left(1.9 \mathrm{mg} \mathrm{kg}^{-1}\right)$ at the last and first harvest with an increase at the second sampling. The shoot $\mathrm{P}$ concentration of oilseed rape decreased in both soils from $3 \mathrm{mg} \mathrm{kg}^{-1}$ at the first harvest to $2.2 \mathrm{mg} \mathrm{kg}^{-1}$ in the Regosol and even down to $1.4 \mathrm{mg} \mathrm{kg}^{-1}$ in the Eutric Fluvisol at the third harvest. Phosphorus uptake per plant (Figure 2) continuously significantly increased from the first to the third harvest for both species.

Table 1. Shoot biomass and $\mathrm{P}$ concentration of maize and oilseed rape grown in a sand (Regosol) and loam (Eutric Fluvisol )soil harvested at three different dates. Data are means of four replicates $\pm \mathrm{SE}$

\begin{tabular}{|c|c|c|c|c|}
\hline Crop & Soil & Harvest at DAT & $\begin{array}{l}\text { Shoot biomass } \\
- \text { S pot }^{-1}- \\
\end{array}$ & Shoot P concentration \\
\hline \multirow[t]{6}{*}{ Maize } & Regosol & 24 & $4.7 \pm 0.2 \mathrm{a}$ & $2.4 \pm 0.03 b$ \\
\hline & & 42 & $14.7 \pm 0.6 \mathrm{~b}$ & $1.7 \pm 0.09 \mathrm{a}$ \\
\hline & & 70 & $54.4 \pm 3.7 \mathrm{c}$ & $1.6 \pm 0.10 \mathrm{a}$ \\
\hline & Eutric Fluvisol & 24 & $2.8 \pm 0.1 \mathrm{a}$ & $1.9 \pm 0.04 \mathrm{a}$ \\
\hline & & 42 & $6.5 \pm 0.4 b$ & $2.5 \pm 0.07 \mathrm{~b}$ \\
\hline & & 70 & $32.8 \pm 2.3 \mathrm{c}$ & $1.9 \pm 0.03 \mathrm{a}$ \\
\hline \multirow[t]{6}{*}{ Oilseed rape } & Regosol & 28 & $8.0 \pm 0.5 \mathrm{a}$ & $3.2 \pm 0.20 \mathrm{~b}$ \\
\hline & & 42 & $23.2 \pm 0.4 \mathrm{~b}$ & $2.6 \pm 0.03 \mathrm{a}$ \\
\hline & & 56 & $34.5 \pm 1.8 \mathrm{c}$ & $2.2 \pm 0.13 \mathrm{a}$ \\
\hline & Eutric Fluvisol & 28 & $9.8 \pm 0.7 \mathrm{a}$ & $2.9 \pm 0.14 \mathrm{c}$ \\
\hline & & 42 & $24.6 \pm 0.9 b$ & $2.1 \pm 0.08 b$ \\
\hline & & 56 & $39.6 \pm 1.8 \mathrm{c}$ & $1.4 \pm 0.05 \mathrm{a}$ \\
\hline
\end{tabular}

Small letters indicate a significant difference among harvests in the same soil and crop (P value $<0.05)$. DAT $=$ days after transplanting. 

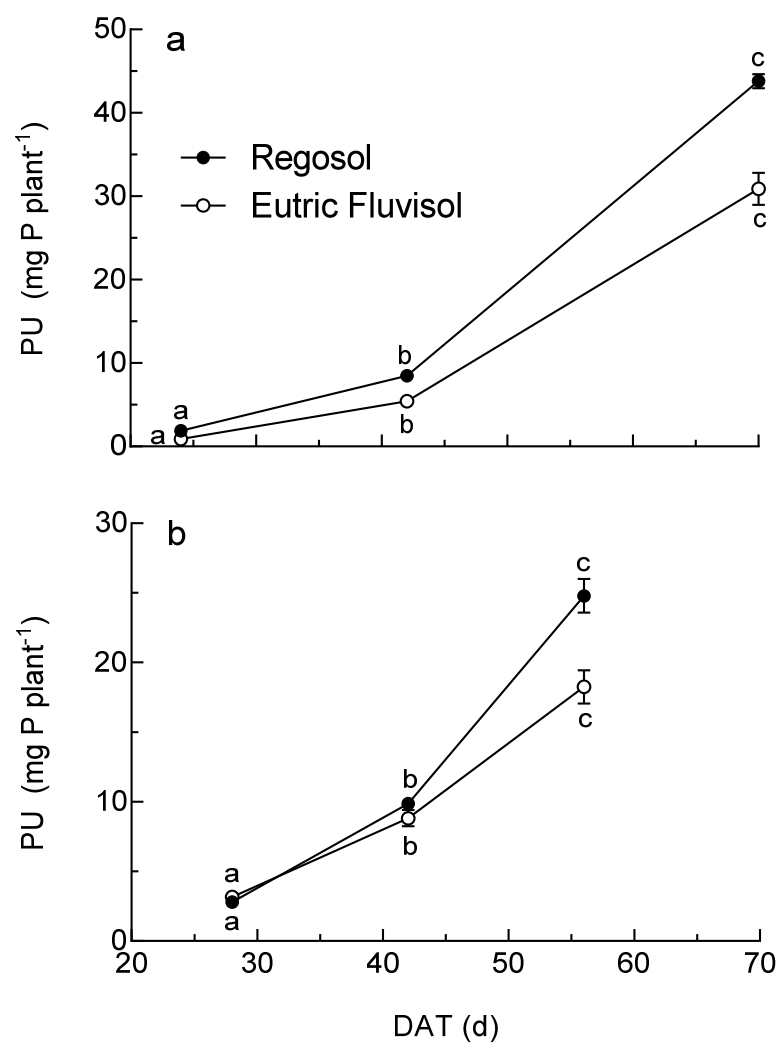

Figure 2. Phosphorus uptake (PU) of maize (a) and oilseed rape (b) growing in two soils and at three growth stages. DAT $=$ days after transplanting. Different letters denote significant differences among the harvests for the same soil (Tukey test, $\mathrm{P}<0.05$ ). Values are means $\pm \mathrm{SE}$ of 4 replicates.

3.2. Phosphorus fractions in the rhizosphere and in the bulk soil

The concentration of organic $\left(\mathrm{P}_{\mathrm{o}}\right)$ and inorganic $\left(\mathrm{P}_{\mathrm{i}}\right)$ $\mathrm{P}$ fractions in the rhizosphere and in the bulk soil is shown in Table 2. In the Regosol the alkali $\left(\mathrm{NaHCO}_{3}\right.$ and $\mathrm{NaOH}$ ) soluble $\mathrm{P}_{\mathrm{i}}$ fractions dominate while in the Eutric Fluvisol the acid $(\mathrm{HCl})$ soluble $\mathrm{P}$ were most important. 
Table 2. Concentrations of inorganic $\left(\mathrm{P}_{\mathrm{i}}\right)$ and organic $\left(\mathrm{P}_{\mathrm{o}}\right) \mathrm{P}$ fractions in the rhizosphere at three harvests of maize and oilseed rape in comparison with bulk soil in an acid sand (Regosol) and neutral loam (Eutric Fluvisol) soil. Data are means of four replicates $\pm \mathrm{SE}$.

\begin{tabular}{|c|c|c|c|c|c|c|c|}
\hline & & \multicolumn{2}{|c|}{ First harvest } & \multicolumn{2}{|c|}{ Second harvest } & \multicolumn{2}{|c|}{ Third harvest } \\
\hline & & Bulk soil & Rhizosphere soil & Bulk soil & Rhizosphere soil & Bulk soil & Rhizosphere soil \\
\hline Maize & & & & mg P & oil $)^{-1}$ & 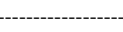 & - \\
\hline \multirow[t]{5}{*}{ Regosol } & $\mathrm{NaHCO}_{3}-\mathrm{Pi}$ & $72.8 \pm 0.7$ & $58.9 \pm 1.9^{*}$ & $65.1 \pm 1.7$ & $54.0 \pm 2.2^{*}$ & $65.0 \pm 4.2$ & $49.1 \pm 0.3^{*}$ \\
\hline & $\mathrm{NaHCO}_{3}-\mathrm{Po}$ & $43.6 \pm 0.9$ & $43.1 \pm 1.5$ & $40.3 \pm 4.0$ & $40.6 \pm 6.1$ & $26.0 \pm 1.2$ & $31.0 \pm 2.0$ \\
\hline & $\mathrm{NaOH}-\mathrm{Pi}$ & $129.8 \pm 4.4$ & $101.4 \pm 1.3^{*}$ & $128.4 \pm 9.5$ & $102.3 \pm 3.9^{*}$ & $119.8 \pm 4.5$ & $80.8 \pm 3.6^{*}$ \\
\hline & $\mathrm{NaOH}-\mathrm{Po}$ & $112.7 \pm 2.9$ & $89.0 \pm 1.5^{*}$ & $113.4 \pm 8.7$ & $109.0 \pm 6.1$ & $124.7 \pm 2.9$ & $92.5 \pm 4.0^{*}$ \\
\hline & $\mathrm{HCl}-\mathrm{Pi}$ & $77.9 \pm 3.5$ & $76.8 \pm 2.5$ & $71.1 \pm 2.4$ & $82.4 \pm 4.4$ & $64.8 \pm 1.9$ & $75.4 \pm 2.7^{*}$ \\
\hline \multirow[t]{5}{*}{ Eutric Fluvisol } & $\mathrm{NaHCO}_{3}-\mathrm{Pi}$ & $50.0 \pm 3.9$ & $36.1 \pm 1.3^{*}$ & $42.4 \pm 2.3$ & $31.2 \pm 0.6^{*}$ & $35.7 \pm 1.1$ & $32.1 \pm 1.6$ \\
\hline & $\mathrm{NaHCO}_{3}-\mathrm{Po}$ & $18.8 \pm 3.9$ & $24.2 \pm 1.8$ & $17.8 \pm 5.7$ & $19.0 \pm 2.5$ & $11.5 \pm 1.1$ & $17.7 \pm 2.3$ \\
\hline & $\mathrm{NaOH}-\mathrm{Pi}$ & $41.3 \pm 1.2$ & $39.8 \pm 1.7$ & $50.6 \pm 2.8$ & $43.2 \pm 2.5$ & $43.3 \pm 1.1$ & $35.3 \pm 0.4^{*}$ \\
\hline & $\mathrm{NaOH}-\mathrm{Po}$ & $47.2 \pm 1.9$ & $51.3 \pm 2.7$ & $58.1 \pm 6.0$ & $61.5 \pm 1.6$ & $57.0 \pm 1.3$ & $66.7 \pm 1.7^{*}$ \\
\hline & $\mathrm{HCl}-\mathrm{Pi}$ & $167.0 \pm 1.1$ & $174.7 \pm 3.9$ & $160.6 \pm 2.0$ & $160.3 \pm 2.9$ & $167.9 \pm 4.5$ & $158.9 \pm 3.3$ \\
\hline \multicolumn{8}{|l|}{ Oilseed rape } \\
\hline \multirow[t]{5}{*}{ Regosol } & $\mathrm{NaHCO}_{3}-\mathrm{Pi}$ & $52.0 \pm 0.9$ & $44.1 \pm 2.4^{*}$ & $76.7 \pm 2.7$ & $56.8 \pm 2.4^{*}$ & $70.1 \pm 3.4$ & $61.3 \pm 3.6$ \\
\hline & $\mathrm{NaHCO}_{3}-\mathrm{Po}$ & $35.8 \pm 1.2$ & $37.4 \pm 2.6$ & $53.9 \pm 13.9$ & $42.5 \pm 2.8$ & $30.8 \pm 0.8$ & $33.8 \pm 1.3$ \\
\hline & $\mathrm{NaOH}-\mathrm{Pi}$ & $123.4 \pm 3.9$ & $116.4 \pm 2.0$ & $111.7 \pm 5.7$ & $92.4 \pm 4.2^{*}$ & $98.6 \pm 1.8$ & $90.6 \pm 2.9$ \\
\hline & $\mathrm{NaOH}-\mathrm{Po}$ & $90.7 \pm 7.1$ & $80.9 \pm 9.2$ & $84.2 \pm 2.4$ & $74.5 \pm 12.1$ & $122.7 \pm 7.7$ & $111.5 \pm 5.0$ \\
\hline & $\mathrm{HCl}-\mathrm{Pi}$ & $67.4 \pm 0.9$ & $67.7 \pm 0.3$ & $72.3 \pm 3.7$ & $77.9 \pm 6.2$ & $63.9 \pm 3.0$ & $62.6 \pm 1.5$ \\
\hline \multirow[t]{5}{*}{ Eutric Fluvisol } & $\mathrm{NaHCO}_{3}-\mathrm{Pi}$ & $32.2 \pm 0.6$ & $25.5 \pm 0.8^{*}$ & $47.5 \pm 0.5$ & $37.5 \pm 0.9^{*}$ & $47.2 \pm 1.4$ & $35.8 \pm 0.6^{*}$ \\
\hline & $\mathrm{NaHCO}_{3}-\mathrm{Po}$ & $21.5 \pm 0.1$ & $22.7 \pm 1.2$ & $24.8 \pm 0.4$ & $27.4 \pm 1.7$ & $13.6 \pm 1.4$ & $14.1 \pm 0.6$ \\
\hline & $\mathrm{NaOH}-\mathrm{Pi}$ & $42.8 \pm 1.0$ & $37.8 \pm 0.8^{*}$ & $42.3 \pm 0.3$ & $37.0 \pm 0.5^{*}$ & $36.7 \pm 1.1$ & $34.8 \pm 0.6$ \\
\hline & $\mathrm{NaOH}-\mathrm{Po}$ & $31.0 \pm 1.2$ & $32.7 \pm 0.4$ & $31.7 \pm 2.5$ & $32.7 \pm 0.6$ & $33.7 \pm 2.8$ & $28.5 \pm 1.0$ \\
\hline & HCl-Pi & $189.4 \pm 8.0$ & $175.1 \pm 6.9$ & $183.2 \pm 5.0$ & $179.0 \pm 6.2$ & $163.6 \pm 4.8$ & $168.0 \pm 3.4$ \\
\hline
\end{tabular}

*means a significant difference between rhizosphere and bulk soil $(\mathrm{P}$ value $<0.05)$.

Plants affected the $\mathrm{P}$ fractions in soil. The least affected were the $\mathrm{P}_{\mathrm{o}}$, oilseed rape did not affect any of the $\mathrm{P}_{\mathrm{o}}$ fractions and maize affected the $\mathrm{NaOH}-\mathrm{P}_{\mathrm{o}}$ fraction only. It was decreased in the Regosol, and in the Eutric Fluvisol a small increase at the last harvest was observed.

The $\mathrm{P}_{\mathrm{i}}$ fractions were much more affected and, for a better understanding, the changes caused by the plants are shown graphically in Figure 3.

Maize, in the Regosol, significantly depleted $\mathrm{NaH}-$ $\mathrm{CO}_{3}-\mathrm{P}_{\mathrm{i}}$ and $\mathrm{NaOH}-\mathrm{P}_{\mathrm{i}}$ in the rhizosphere at all three harvests (Figure 3). There was no significant change in $\mathrm{HCl}-\mathrm{P}_{\mathrm{i}}$ at the first two harvests, while at 70 DAT significant accumulation was observed. The degree of depletion of all three fractions did not change with plant age. In the Eutric Fluvisol at the first and second harvests, maize only decreased the $\mathrm{NaHCO}_{3}-\mathrm{P}_{\mathrm{i}}$, while at the third harvest only the depletion of $\mathrm{NaOH}$ $\mathrm{P}_{\mathrm{i}}$ was significant. No significant depletion or accumulation of HCl- $\mathrm{P}_{\mathrm{i}}$ was observed in the rhizosphere at the three harvests in relation to the bulk soil.

For oilseed rape, in the acid Regosol the depletion of $\mathrm{NaHCO}_{3}-\mathrm{P}_{\mathrm{i}}$ increased from the first to second harvest but decreased to non-significant at the third harvest (Figure 3). The depletion of NaOH-P $\mathrm{P}_{\mathrm{i}}$ in this soil was only significant at the second harvest. Oilseed rape did not deplete nor accumulated $\mathrm{HCl}-\mathrm{P}_{\mathrm{i}}$ in this soil. In the neutral Eutric Fluvisol the depletion of $\mathrm{NaHCO}_{3}-\mathrm{P}_{\mathrm{i}}$ by oil seed rape increased from young (first harvest) to older plants (third harvest). No significant depletion or accumulation of $\mathrm{HCl}-\mathrm{P}_{\mathrm{i}}$ was observed at any harvest. 

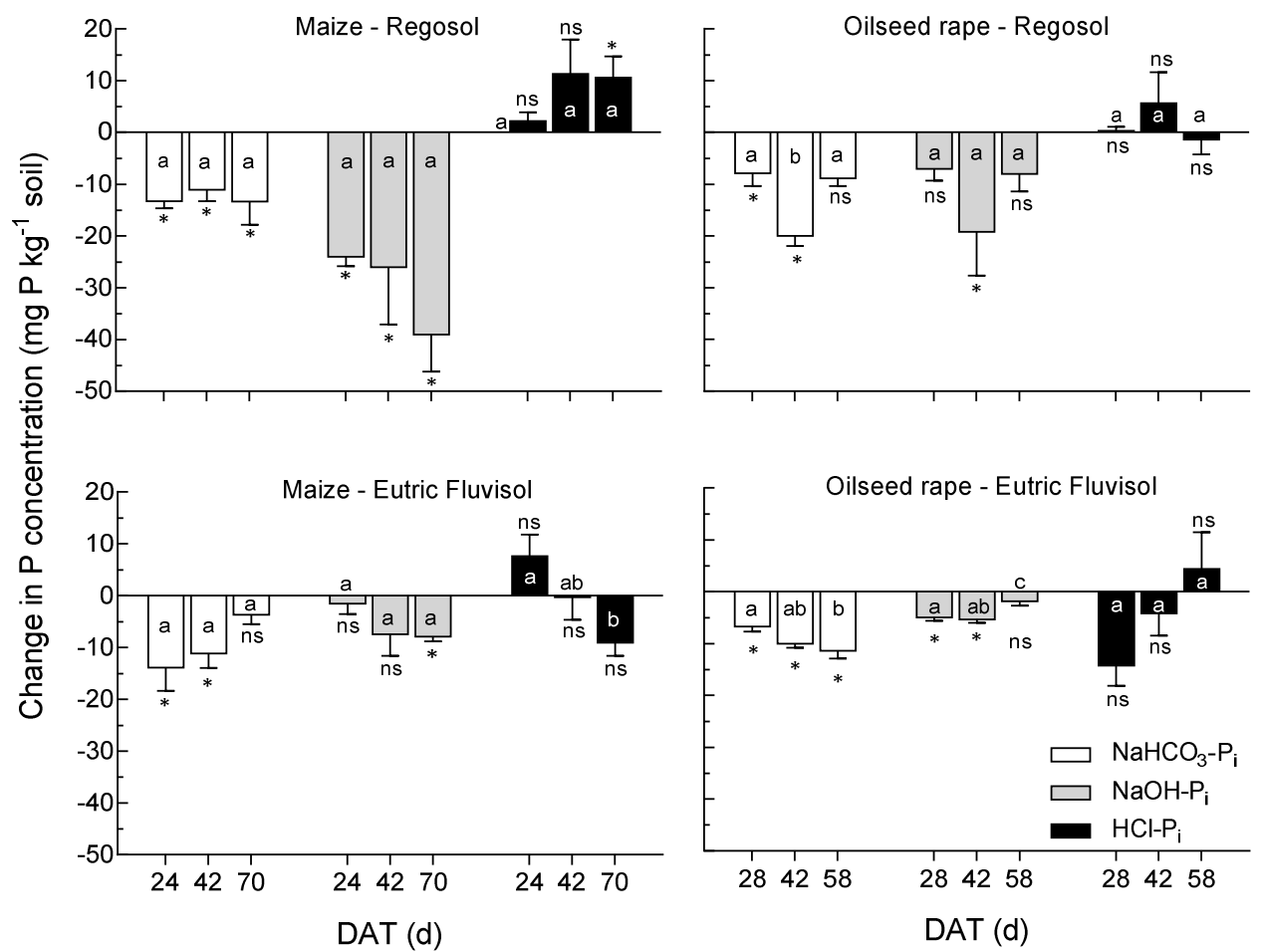

Figure 3. Change (depletion or accumulation) of inorganic P fractions in the rhizosphere of maize and oilseed rape at three growth stages (DAT= days after transplanting) and in two soils. Different small letters denote a significant change of the $\mathrm{P}$ fraction at different harvests (Tukey test, $\mathrm{P}<0.05$ ), * indicates a significant change of the $\mathrm{P}$ fraction in the rhizosphere in relation to the $\mathrm{P}$ content in bulk soil $(t$-test, $\mathrm{P}<0.05)$ and ns means not significant change. Values are means $\pm \mathrm{SE}$ of 4 replicates.

To characterize the extent to which a $\mathrm{P}$ fraction was plant available, its depletion in the rhizosphere was expressed as a percentage of the concentration in the bulk soil (Figure 4). The figure shows the relative depletion of the $\mathrm{NaHCO}_{3}-\mathrm{P}_{\mathrm{i}}$ and $\mathrm{NaOH}-\mathrm{P}_{\mathrm{i}}$ fractions, which were significantly depleted according to Table 2. In the Regosol, $\mathrm{NaHCO}_{3}-\mathrm{P}_{\mathrm{i}}$ and $\mathrm{NaOH}-\mathrm{P}_{\mathrm{i}}$ were similarly depleted by about $20 \%$, and this by both species, indicating that both fractions were similarly plant available in that soil and that none of the species had a higher capacity to acquire $\mathrm{P}$ from these $\mathrm{P}$ fractions. In the neutral loamy soil, however, $\mathrm{NaOH}$ $\mathrm{P}_{\mathrm{i}}$ was depleted less than $\mathrm{NaHCO}_{3}-\mathrm{P}_{\mathrm{i}}$ indicating that $\mathrm{NaOH}-\mathrm{P}_{\mathrm{i}}$ was less available to plants. The depletion of $\mathrm{NaHCO}_{3}-\mathrm{P}_{\mathrm{i}}$ was around $23 \%$ while that of $\mathrm{NaOH}$ $\mathrm{P}_{\mathrm{i}}$ around $15 \%$. 


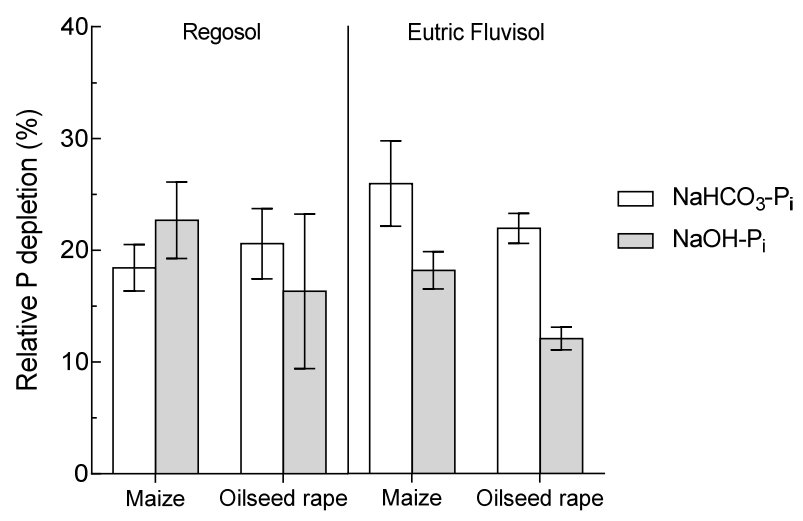

Figure 4. The depletion of the $\mathrm{NaHCO}_{3}-\mathrm{P}_{\mathrm{i}}$ and $\mathrm{NaOH}-\mathrm{P}_{\mathrm{i}}$ fractions expressed as percentage of their concentration of the bulk soil which may be considered as a measure of their availability to the plants of maize or oil seed rape. Values are averages of the significant depletions of Figure 3. Values are means \pm SE.

\section{Discussion}

\subsection{Plant growth and Experimental set-up}

Shoot biomass and phosphorus uptake (PU) increased with plant age for maize and oilseed rape (Table 1, Figure 2). The PU in both plant species increased strongly up to the last harvest, indicating that maximum uptake had not been reached. For both plant species, PU was higher in the acid than in the neutral soil, although similar amounts of plant available $\mathrm{P}$ were detected in both soils (Table 1). This indicates that besides available (calcium-acetate-lactate) $\mathrm{P}$ other soil properties affected plant growth and $\mathrm{P}$ uptake. The shoot $\mathrm{P}$ concentration (Table 1) of maize between 1.6 and $2.4 \mathrm{mg} \mathrm{kg}^{-1}$ as well as those of oilseed rape of 1.4 and $3.2 \mathrm{mg} \mathrm{kg}^{-1}$ are in the range of deficiency (Bergmann, 1992). Singh (2003) found in the field experiment, which was the major starting point of our research, that only $\mathrm{P}$ deficient maize plants with a shoot $\mathrm{P}$ concentration of around $2 \mathrm{mg} \mathrm{kg}^{-1}$ increased the $\mathrm{P}$ influx by 6 times when becoming older while the well $\mathrm{P}$ supplied plants with about $5 \mathrm{mg} \mathrm{kg}^{-1}$ did not show that increased $\mathrm{P}$ influx. Thus, we expected that the maize plants in our experiment would also have increased their P mobilizing capability when becoming older and therefore accessing $\mathrm{P}$ fractions in the rhizosphere younger plants were unable to. In oilseed rape the $\mathrm{P}$ deficiency may have induced an exudation of organic acids (Hoffland et al., 1989) causing a strong depletion of Ca-bound $\mathrm{P}$ in the rhizosphere.

\subsection{Changes of $P$ fractions in the rhizosphere}

To obtain rhizosphere soil, different approaches have been used. Already in 1971 Riley and Barber (1971) but even more recently Rose et al. (2010) obtained rhizosphere soil by separating the soil adhering to roots that had been separated carefully from the bulk soil. The soil obtained in this way is partly actual rhizophere soil but will also contain some bulk soil. In contrast, other studies (George et al., 2002; Hedley et al., 1982) obtained rhizosphere soil by concentrating the entire root system in a small soil volume forcing many roots on a fine cloth of 20-30 $\mu \mathrm{m}$ mesh. The soil on the other side of the mesh could be separated into 
layers of different distance from the simulated planar root surface and in that way a concentration profile of the nutrient under investigation is obtained. However, the strong restriction of the root system did not allow for a normal growth of the plants over a longer period of time as was intended in our experiment. Therefore, we chose a set up (Figure 1) which forced only part of the root system on a fine meshed cloth while a large portion of the roots grew without restriction allowing for a close to normal development of the plants. In this way we expected to obtain rhizosphere soil from plants of different age and possibly with different $P$ mobilizing strategy that would explain the strong increase in P influx observed in the field (Bhadoria et al., 2001; Claassen et al., 1990).

The results show that both plant species in both soils only used alkali soluble $\mathrm{P}_{\mathrm{i}}\left(\mathrm{NaHCO}_{3}-\mathrm{P}_{\mathrm{i}}\right.$ and $\mathrm{NaOH}$ $-\mathrm{P}_{\mathrm{i}}$ ), which are often referred to as $\mathrm{Fe}$ and $\mathrm{Al}$ phosphate (Figure 3). There was no depletion of acid soluble $\mathrm{P}_{\mathrm{i}}\left(\mathrm{HCl}-\mathrm{P}_{\mathrm{i}}\right)$, often referred to as Ca phosphate, even in the Eutric Fluvisol where the concentration of HCl- $\mathrm{P}_{\mathrm{i}}$ was twice that of total alkali soluble $\mathrm{P}_{\mathrm{i}}$. In one case even an accumulation of HCl-P ${ }_{i}$ occurred. The exclusive use of alkali soluble $\mathrm{P}$ and not of $\mathrm{HCl}-\mathrm{P}_{\mathrm{i}}$ by plants confirms findings made by Hedley et al. (1982) using a similar experimental setup. The different plant availability of the $\mathrm{P}$ fractions may be because alkali soluble $\mathrm{P}_{\mathrm{i}}$ is sorbed to $\mathrm{Fe}$ and $\mathrm{Al}$ oxides/hydroxides surfaces in an exchangeable manner, as they are isotopically exchangeable (Bühler et al, 2002., Machold 1962 , 1963). In contrast, $\mathrm{HCl}-\mathrm{P}_{\mathrm{i}}$ is almost inaccessible to isotopic exchange and therefore not accessible for immediate plant uptake, except in soils with a pH (KCl) clearly above 7 (Bühler et al., 2002). It has been reported that a significant proportion of acid soluble $\mathrm{P}_{\mathrm{i}}$ can be depleted by rice roots, but only under submerged soil conditions where $\mathrm{Fe}^{3+}$ reduction and $\mathrm{NH}_{4}^{+}$uptake caused a strong acidification of the rhizosphere (Saleque and Kirk, 1995; Zhang et al., 2006).

Our results did not confirm the hypothesis that oilseed rape would use $\mathrm{HCl}-\mathrm{P}_{\mathrm{i}}$ (Ca-bound $\mathrm{P}$ ) because of its ability to acidify the rhizosphere as found by Hoffland et al. (1989). This contradicting result may be related to that Hoffland et al. (1989) had used a sand culture which has no $\mathrm{pH}$ buffer capacity while in the soils used in the present experiment, and more so in the Eutric Fluvisol, the buffering of the soil $\mathrm{pH}$ may have resulted in only small $\mathrm{pH}$ changes in the rhizosphere which were not sufficient to solubilise $\mathrm{HCl}-\mathrm{P}_{\mathrm{i}}$. In the present experiment, instead of a depletion there was a tendency for $\mathrm{HCl}-\mathrm{P}_{\mathrm{i}}$ accumulation, mainly in the Regosol, which was even statistically significant for maize (Figure 3). This may be related to the fact that $\mathrm{Ca}$ often accumulates in the rhizosphere by mass flow (Jungk and Claassen, 1997).

The results of this and previous studies show that in short term experiments, acid soluble $\mathrm{P}\left(\mathrm{HCl}-\mathrm{P}_{\mathrm{i}}\right)$ is not used by plants unless the rhizosphere is strongly acidified. However, in long term experiments $(>10$ years), $\mathrm{HCl}-\mathrm{P}_{\mathrm{i}}$ is depleted together with alkali-soluble $\mathrm{P}_{\mathrm{i}}$ (Myint, 2005). This indicates that $\mathrm{HCl}-\mathrm{P}_{\mathrm{i}}$ solubilisation without acidification is not fast enough to become dissolved in significant amounts within days or a few weeks during $\mathrm{P}$ uptake by the root but on a long-term basis of several years $\mathrm{HCl}-\mathrm{P}_{\mathrm{i}}$ can replenish the $\mathrm{P}$ removed by roots from other more labile $\mathrm{P}$ fractions.

\subsection{Plant availability of different $P$ fractions}

The sequential fractionation used in this experiment is a variation of the widely used method developed by Hedley et al. (1982). It is based on the assumption that extractant strength is related to the plant availability of $\mathrm{P}$ (Zhang et al., 2006). Thus, the readily available $\mathrm{P}$ fraction is extracted by $\mathrm{NaHCO}_{3}$, whereas $\mathrm{P}$ extracted by $\mathrm{NaOH}$ is less available and is most likely strongly 
associated with $\mathrm{Al}$ and $\mathrm{Fe}$ hydrous oxides. The $\mathrm{P}$ extracted with $\mathrm{HCl}$, which is thought to be bound to $\mathrm{Ca}$, is assumed to be the least plant available (Hedley et al., 1982).

To assess the plant availability of a P fraction we used the degree of depletion, i.e. the depletion expressed as $\%$ of the total concentration of that fraction. In the acid sandy soil in the present study, the percentage depletion of $\mathrm{NaHCO}_{3}-\mathrm{P}_{\mathrm{i}}$ was similar to that of $\mathrm{NaOH}-$ $\mathrm{P}_{\mathrm{i}}$ for both plant species (Figure 4), indicating that both $\mathrm{P}$ fractions were similarly accessible, contradicting the assumptions mentioned above. However, in the neutral loamy soil $\mathrm{NaOH}-\mathrm{P}_{\mathrm{i}}$ was less accessible to plants than $\mathrm{NaHCO}_{3}-\mathrm{P}$, which may indicate stronger bonding of $\mathrm{P}$ to $\mathrm{Fe}$ and $\mathrm{Al}$ in that soil than in the acid soil. This may be because $\mathrm{P}$ sorption in some alkaline soil is also controlled by $\mathrm{Al}$ and Fe oxides, as shown by Bertrand et al. (2003), and not only by Ca. This shows that the plant availability of the alkali soluble $\mathrm{P}_{\mathrm{i}}$ fractions cannot be generalized for all soils.

The HCl- $\mathrm{P}_{\mathrm{i}}$ was not accessible to plants in any of the two soils. This is because acid soluble P in acid to neutral soils is not accessible to isotopic exchange (Machold 1962, 1963) and thereby not accessible to direct plant uptake unless it would be solubilised by soil acidification (Saleque and Kirk, 1995).

Even though the plants used $\mathrm{NaHCO}_{3}-\mathrm{P}_{\mathrm{i}}$ and $\mathrm{NaOH}-$ $\mathrm{P}_{\mathrm{i}}$, they only depleted it by $1226 \%$ at most (Figure 4). Others have reported similar results (Gahoonia and Nielsen, 1992; Hedley et al., 1994). This relatively low exploitation of the alkali-soluble $\mathrm{P}_{\mathrm{i}}$, even though the 'planar' root causes a strong concentration decrease in soil solution (Claassen and Steingrobe, 1999; Hendriks et al., 1981), may be related to the following. For one, only part of the alkali-soluble $\mathrm{P}$ is isotopically exchangeable (Bühler et al., 2002) and thereby plant available and furthermore, $30-40 \%$ of this isotopically exchangeable $\mathrm{P}$ would not be plant available because its equilibrium $\mathrm{P}$ concentration in soil solution is below

\subsection{Effect of plant age on P fraction depletion}

Figure 3 shows that maize only depleted the alkali soluble $\mathrm{P}_{\mathrm{i}}\left(\mathrm{NaHCO}_{3}-\mathrm{P}_{\mathrm{i}}\right.$ and $\left.\mathrm{NaOH}-\mathrm{P}_{\mathrm{i}}\right)$ in both soils. But against our hypothesis older plants did not access other $\mathrm{P}$ fractions than younger plants nor was the $\mathrm{P}$ depletion clearly stronger, there only was a tendency for older plants to have a stronger depletion of the $\mathrm{NaOH}-\mathrm{P}_{\mathrm{i}}$ in the acid sandy soil, and in the neutral soil this fraction was only significantly depleted by older plants. Therefore, there is only an indication that older maize plants may to a small extent have a stronger depletion of the $\mathrm{NaOH}-\mathrm{P}_{\mathrm{i}}$.

One reason for this only negligible effect of plant age on the P depletion by maize may be related to the experimental conditions of using a 'planar' root surface as compared to the cylindrical geometry of a single root growing in soil. The rhizosphere, i.e. the portion of soil influenced by the root concerning $\mathrm{P}$, was in our experiment only $1 \mathrm{~mm}$, which is close to values of Hendriks et al. (1981) but smaller than 2-4 mm of Hedley et al. (1994). The amount of soil volume within the range of the $\mathrm{P}$ depletion is much higher for cylindrical than for planar root surfaces. In the case of depletion of $1 \mathrm{~mm}$ one can calculate that the soil volume of the rhizosphere per unit root surface area (soil volume within $1 \mathrm{~mm}$ from the root surface) would be about 6 times higher for a cylindrical root with a radius of $0.1 \mathrm{~mm}$ than for a planar root. The difference would be even more for a rhizosphere wider than 1 mm (Jungk and Claassen, 1997). Because of the small volume of the planar rhizosphere it will rapidly get depleted down to a possible minimum already in an early growth stage.

Another reason for not finding a change in P fraction depletion even though in the field the $\mathrm{P}$ influx was several times higher in older than in younger plants is that the nutrient influx depends on the nutrient flux to the root surface which is mostly related to the nutrient 
concentration in the soil solution and not so much on the quantity of available nutrient in the soil (Bhadoria et al., 2002). Maize in the field may have increased the $\mathrm{P}$ soil solution concentration in the rhizosphere, increasing the transport to the root without necessarily causing a stronger depletion of the available P close to the root surface. An increase of $\mathrm{P}$ soil solution concentration by, e.g. organic acids as exuded by roots, has been shown in several studies (Hinsinger, 2001).

\section{Conclusions}

In both, the acid (Regosol) and the neutral soil (Eutric Fluvisol), the only $\mathrm{P}$ fractions that were depleted in the rhizosphere of maize and oilseed rape were the alkali soluble $\mathrm{P}\left(\mathrm{NaHCO}_{3}-\mathrm{P}_{\mathrm{i}} \text { and } \mathrm{NaOH}-\mathrm{P}\right)_{\mathrm{i}}$. In the Regosol both fractions were similarly plant available whereas in the Eutric Fluvisol the $\mathrm{NaOH}-\mathrm{P}_{\mathrm{i}}$ was less available than the $\mathrm{NaHCO}_{3}-\mathrm{P}_{\mathrm{i}}$. The acid soluble $\mathrm{P}$ $\left(\mathrm{HCl}-\mathrm{P}_{\mathrm{i}}\right)$ was not depleted in the rhizosphere of maize or oilseed rape. Plant growth stage had no effect on the $\mathrm{P}$ fractions depleted or on the intensity of their depletion in the rhizosphere.

\section{References}

Adhami, E., Owliaie, H.R., Molavi, R., Rezaei Rashti, M., Esfandbod, M. 2013. Effects of soil properties on phosphorus fractions in subtropical soils of Iran. J. Soil Sci. Plant Nutr. 13, 11-21.

Bergmann, W. 1992. Nutritional disorders of plants: development, visual and analytical diagnosis. Jena, New York, Gustav Fischer.

Bertrand, I., Holloway, R.E., Armstrong, R.D., McLaughlin, M.J. 2003. Chemical characteristics of phosphorus in alkaline soils from southern Australia. Soil Res. 41, 61-76.
Bhadoria, P.B.S., Singh, S., Claassen, N. 2001. Phosphorus efficiency of wheat, maize and groundnut grown in low phosphorus-supplying soil. In Plant Nutrition, W. J. Horst, M .K. Schenk, A. Bürkert, N. Claassen, H. Flessa, W. B. Frommer, H. Goldbach, H.-W. Olfs, V. Römheld, B. Sattelmacher, et al., eds. Springer Netherlands. pp. 530-531.

Bhadoria, P.S., Steingrobe, B., Claassen, N., Liebersbach, H. 2002. Phosphorus efficiency of wheat and sugar beet seedlings grown in soils with mainly calcium, or iron and aluminium phosphate. Plant Soil. 246, 41-52.

Bühler, S., Oberson, A., Rao, I.M., Friesen, D.K., Frossard, E. 2002. Sequential phosphorus extraction of a 33P-labeled Oxisol under contrasting agricultural systems. Soil Sci. Soc. Am. J. 66, 868-877.

Cabeza, R.A., Steingrobe, B., Römer, W., Claassen, N. 2013. Plant availability of isotopically exchangeable and isotopically nonexchangeable phosphate in soils. J. Plant Nutr. Soil Sci. 176, 688-695.

Chang, S.C., Jackson, M.L. 1957. Fractionation of soil phosphorus. Soil Sci. 84, 133-144.

Claassen, N., Steingrobe, B. 1999. Mechanistic simulation models for a better understanding of nutrient uptake from soil. In Mineral Nutrition of Crops: Fundamental Mechanisms and Implications, Z. Rengel, ed. Binghamton, NY: Haworth Herbal Press. pp. 327-367.

Claassen, N., Meyer, D., Jungk, A. 1990. Phosphorus acquisition of field grown sugar beet and its evaluation with a simulation model. In ProceedingsFirst Congress European Soc. Agronomy. Colmar, France. p. O7.

Day, P. 1965. Particle fractionation and particle-size analysis. In Methods of Soil Analysis. Physical and Mineralogical Properties, Including Statistics of Measurement and Sampling, C. Black, ed. 
Madison, WI, American Society of Agronomy. pp. 545-567.

Delgado, M., Zúñiga-Feest, A., Borie, F. 2015. Ecophysiological role of Embothrium coccineum, a Proteaceae species bearing cluster roots, at increasing Phosphorus availability in its rhizosphere. J. Soil Sci. Plant Nutr. 15, 307-320.

Gahoonia, T.S., Nielsen, N. 1992. The effects of rootinduced $\mathrm{pH}$ changes on the depletion of inorganic and organic phosphorus in the rhizosphere. Plant Soil. 143, 185-191.

Gahoonia, T.S., Claassen, N., Jungk, A. 1992a. Mobilization of residual phosphate of different phosphate fertilizers in relation to $\mathrm{pH}$ in the rhizosphere of ryegrass. Fert. Res. 33, 229-237.

Gahoonia, T.S., Claassen, N., Jungk, A. 1992b. Mobilization of phosphate in different soils by ryegrass supplied with ammonium or nitrate. Plant Soil. 140, 241-248.

George, T., Gregory, P., Robinson, J., Buresh, R. 2002. Changes in phosphorus concentrations and $\mathrm{pH}$ in the rhizosphere of some agroforestry and crop species. Plant Soil. 246, 65-73.

Hedley, M.J., Stewart, J.W.B., Chauhan, B.S. 1982. Changes in inorganic and organic soil phosphorus fractions induced by cultivation practices and by laboratory incubations. Soil Sci. Soc. Am. J. 46, 970-976.

Hedley, M.J., Kirk, G.J.R., Santos, M.B. 1994. Phosphorus efficiency and the forms of soil phosphorus utilized by upland rice cultivars. Plant Soil. $158,53-62$.

Helal, H.M. 1990. Varietal differences in root phosphatase activity as related to the utilization of organic phosphates. Plant Soil. 123, 161-163.

Hendriks, L., Claassen, N., Jungk, A. 1981. Phosphatverarmung des wurzelnahen Bodens und Phosphataufnahme von Mais und Raps. Z. Pflanzenernaehr. Bodenk. 144, 486-499.
Hinsinger, P. 2001. Bioavailability of soil inorganic $\mathrm{P}$ in the rhizosphere as affected by root-induced chemical changes: a review. Plant Soil 237, 173195.

Hoffland, E., Findenegg, G.R., Nelemans, J.A. 1989. Solubilization of rock phosphate by rape. Plant Soil. 113, 161-165.

Hoffmann, C., Ladewig, E., Claassen, N., Jungk, A. 1994. Phosphorus uptake of maize as affected by ammonium and nitrate nitrogen - Measurements and model calculations. Z. Pflanzenernaehr. Bodenk. 157, 225-232.

Holford, I.C.R. 1997. Soil phosphorus: its measurement, and its uptake by plants. Soil Res. 35, 227240.

Jungk, A., Claassen, N. 1997. Ion Diffusion in the Soil-Root System. Adv. Agron. 61, 53-110. Machold, O. 1962. Die Pflanzenaufnehmbarkeit des labilen Phosphats. Z. Pflanzenernähr. Bodenk. 98, 99-113.

Machold, O. 1962. Die Pflanzenaufnehmbarkeit des labilen Phosphats. Z. Pflanzenernähr. Bodenk. 98, 99-113.

Machold, O. 1963. Über die Bindungsform des "labilen” Phosphats im Boden. Z. Pflanzenernähr. Bodenk. 103, 132-138.

Murphy, J., Riley, J.P. 1962. A modified single solution method for the determination of phosphate in natural waters. Anal. Chim. Acta. 27, 31-36.

Myint, K. 2005. Short- and long-term P-dynamics of various $\mathrm{P}$-fractions in the field and in the rhizosphere. PhD. University of Göttingen.

Redel, Y., Cartes, P., Demanet, R., Velásquez, G., Poblete-Grant, P., Bol, R., Mora, M.L. 2016. Assessment of phosphorus status influenced by $\mathrm{Al}$ and Fe compounds in volcanic grassland soils. J. Soil Sci. Plant Nutr. 16, 490-506. 
Richardson, A.E., Simpson, R.J. 2011. Soil microorganisms mediating phosphorus availability update on microbial phosphorus. Plant Physiol. 156, 989-996.

Riley, D., Barber, S.A. 1971. Effect of ammonium and nitrate fertilization on phosphorus uptake as related to root-induced $\mathrm{pH}$ changes at the root-soil interface. Soil Sci. Soc. Am. J. 35, 301.

Rose, T.J., Hardiputra, B., Rengel, Z. 2010. Wheat, canola and grain legume access to soil phosphorus fractions differs in soils with contrasting phosphorus dynamics. Plant Soil. 326, 159-170.

Saleque, M.A., Kirk, G.J.D. 1995. Root-induced solubilization of phosphate in the rhizosphere of lowland rice. New Phytol. 129, 325-336.
Scheffer, F., Pajenkamp, H. 1952. Phosphatbestimmung in Pflanzenaschen nach der MolybdänVanadin-Methode. Journal of Plant Nutrition and Soil Science. 56, 2-8.

Schüller, H. 1969. Die CAL-Methode, eine neue Methode zur Bestimmung des pflanzenverfügbaren Phosphates in Böden. Z. Pflanzenernähr. Bodenk. 123, 48-63.

Singh, S. 2003. Phosphorus efficiency of wheat, maize and groundnut in a phosphorus deficient soil. PhD. Indian Institute of Technology.

Zhang, Q., Wang, G.H., Feng, Y.K., Sun, Q.Z., Witt, C., Dobermann, A. 2006. Changes in soil phosphorus fractions in a calcareous paddy soil under intensive rice cropping. Plant Soil. 288, 141-154. 